\title{
Prevalence and factors associated with surfactant use in Brazilian Neonatal Intensive Care Units: A multilevel analysis
}

\author{
Prevalência e fatores associados ao uso de surfactante em unidades \\ de Terapia Intensiva Neonatais brasileiras: análise multinível
}

Ceane Cunha Rios Lessa ${ }^{1}$

Fernando Lamy Filho ${ }^{1}$

Zeni Carvalho Lamy ${ }^{1}$

Antônio Augusto Moura da Silva ${ }^{1}$

Maria Elizabeth Lopes Moreira ${ }^{2}$

Maria Auxiliadora de Souza Mendes Gomes ${ }^{2}$
${ }^{1}$ Departamento de Saúde Pública, Centro de Ciências da Saúde, Universidade Federal do Maranhão. R. Barão de Itapary 155 , Centro. 65020-070 São Luis MA Brasil. ceanecrios@gmail.com

${ }^{2}$ Instituto Fernandes Figueira, Fiocruz. Rio de Janeiro RJ Brasil.

\begin{abstract}
The treatment with exogenous surfactant reduces mortality and the risk of complications in preterm newborns with Respiratory Distress Syndrome. Higher usage levels have been associated with individual and institutional factors. The study aimed to identify these factors associated with use of this technology in 16 public Brazilian Neonatal Units using logistic multilevel analysis. In a sample of 630 newborns the use at some time was $82.6 \%$. Only $24.7 \%$ made use of this technology up to two hours after birth. An intraclass correlation of 0.30 showed that $30 \%$ of the variance in the use of exogenous surfactant could be assigned to the contextual level. In the final model, a greater severity score (SNAPPE-II) was associated with increased surfactant use (OR $=2.64)$, whereas being small for gestational age $(S G A)(O R=0.59)$ was associated with lower use of this technology. At the contextual level the number of beds in the unit $>15(O R=5.86)$, units with higher complexity $(O R=1.73)$ or units with implemented Kangaroo Mother Care $(O R=2.91)$, especially units in Rio de Janeiro state $(O R=$ 16.17) were associated with greater surfactant use. Although individual clinical features explained most of the variation in the use of this technology, factors linked to the institution were also of utmost importance.

Key words Newborn infant, Pulmonary surfactants, Multilevel analysis
\end{abstract}

Resumo O tratamento com surfactante exógeno reduz a mortalidade e o risco de complicações em recém-nascidos com Síndrome de Angústia Respiratória. Maiores níveis de utilização dessa tecnologia têm sido associados tanto a fatores individuais como institucionais. O estudo teve como objetivo identificar esses fatores em 16 unidades neonatais públicas brasileiras usando análise multinível. De 630 recém-nascidos, $82,6 \%$ usaram a tecnologia em algum momento. Apenas 24,7\% fizeram uso até duas horas após o nascimento. Uma correlação intraclasse de 0,30 mostrou que 30\% da variação no uso podem ser atribuídos ao nível contextual. No modelo final, um escore de gravidade maior (SNAPPE-II) foi associado com aumento do uso de surfactante $(O R=2,64)$, enquanto que ser pequeno para a idade gestacional (PIG) $(O R=0,59)$ foi associado a um menor uso dessa tecnologia. No nivel contextual o número de leitos na unidade $>$ $15(\mathrm{OR}=5,86)$, as unidades com mais alta complexidade $(O R=1,73)$ ou unidades com Método Canguru implementado $(O R=2,91)$, especialmente unidades no estado do Rio de Janeiro $(O R=$ 16,17), foram associados com uma maior utilização de surfactante. Embora características individuais tenham explicado a maior parte da variação no uso desta tecnologia, fatores ligados à instituição também foram de extrema importância.

Palavras-chave Recém-nascido, Surfactantes pulmonares, Análise multinível 


\section{Introduction}

In Brazil, the neonatal component of the infant mortality rate remains higher than the post-neonatal one and most of deaths occur in the first seven days of life (early neonatal period). At that stage breathing problems are a major cause of death especially among preterm newborns. In these newborns, lung immaturity determines deficiency of surfactant, a substance responsible for reducing the surface tension within the alveoli that prevents collapse at low lung volumes ${ }^{1}$.

The use of exogenous surfactant is indicated for preterm newborns with established or presumed diagnosis of respiratory distress syndrome (RDS) $)^{2,3}$ because it reduces mortality, disease severity and complications due to RDS. Advantages related to the use of this technology are well established in the literature. It is known that newborns with RDS receiving treatment with surfactant have reduced risk of pneumothorax, pulmonary interstitial emphysema, death and bronchopulmonary dysplasia or death (in combination) in comparison to those who do not receive this treatment ${ }^{4}$.

In a systematic review conducted in 2008, Soll e Morley ${ }^{5}$ have shown that the effectiveness of this technology was linked to the precocity of its use, and that best effects were obtained with its prophylactic use, especially in the delivery room. However, in an updated version of the same review with inclusion of more recent trials and more robust samples, Rojas-Reyes et al. ${ }^{6}$ demonstrated that these results were not maintained when more recent practices like routine use of antenatal maternal steroids and stabilization with CPAP (Continuous Positive Airway Pressure) in the delivery room had been used. However, it has been demonstrated that early therapeutic surfactant administration (in the first two hours of life) leads to a decreased risk of acute lung injury, neonatal death and chronic lung disease compared to delayed treatment in children with well established diagnosis of $\operatorname{RDS}^{7,8}$.

Despite effectiveness and safety of surfactant therapy having been well established ${ }^{9}$, its use presents variations in Neonatal Intensive Care Units (NICU) of different states, regions and countries, which can be due to different protocols regarding its use, what may lead to distinct clinical outcomes ${ }^{10}$. Kaplan et al. ${ }^{11}$ in 2011 in Cincinnati, US, found a surfactant use rate of $46 \%$ among 3,633 preterm infants with RDS in 16 different hospitals, demonstrating large variations between them. Higher usage levels were associated with factors linked to individual characteristics (being Caucasian or male) as well as with factors linked to the institution (hospitals with higher numbers of hospitalizations of extremely low birth weight newborns per year had higher usage rates). Similarly, Howell et al. in $2010^{12}$ reported an association between non-receipt of this technology and individual (being of Afro-American origin or having high birth weight) as well as institutional characteristics (the children's birth hospital).

In recent years, in Brazil, only Rebello et al. ${ }^{13}$ and Menezes et al. ${ }^{14}$ reported exogenous surfactant use rate. Rebello found a 39.1\% surfactant use rate among newborns $<1500 \mathrm{~g}$ at birth and Menezes reported a $51.8 \%$ rate in newborns with a mean birth weight of $1365 \pm 283 \mathrm{~g}$. However, the authors did not investigate determinants of use of this technology.

Determining the role of institutional (related to the hospital) and individual (maternal and newborn characteristics) factors regarding the use of replacement therapy with exogenous surfactant in newborns with hyaline membrane disease are important to the implementation of public policies and establishing effective routines in the treatment of RDS and has not been investigated to date in Brazil. Thus, this study aimed to identify institutional and individual factors associated with use of this technology in 16 public Brazilian NICU, using multilevel analysis, a type of regression that takes into account the hierarchical structure of data.

\section{Methods}

We conducted a sectional study using the database of the research "Evaluation of the results of neonatal care from the perspective of humanized care for newborns with low birth weight - Kangaroo Mother Care" held from March/2004 to March/2005. The Ministry of Health/Pan American Health Organization (PAHO) funded the research. Sixteen public Brazilian Neonatal Units participated in the study. Twelve units were located in the Southeast, two in the South and two in the Northeast region.

The units were selected according to the original research. The selection was based on the 8 hospitals affiliated to the Brazilian Neonatal Research Network at the time, who did not use the Kangaroo Mother Care method, and were considered public centers of excellence in Brazil. The other eight units had deployed the Kangaroo Method and were considered national reference units for the KMC. 
In the original study, all newborns with birth weight between 500 and $1749 \mathrm{~g}$ were included, for 1,429 individuals over a period of one year. Those with major malformations, congenital infection of the TORCH (toxoplasmosis, rubella, cytomegalovirus, herpes and syphilis) group, chromosomal abnormalities, metabolic syndromes, severe perinatal encephalopathy or necrotizing enterocolitis requiring surgery were not included.

A sample of newborns with RDS was selected for this study (630 newborns from 1,429 of the original sample). The diagnosis was determined by gas analysis, radiological and clinical signs of respiratory distress. Patients were considered to present RDS if they presented $\mathrm{PaO} 2<50-\mathrm{mmHg}$ or central cyanosis in room air or needed supplemental oxygen to maintain their $\mathrm{PaO} 2>50$ $\mathrm{mmHg}$ and a chest X-ray showing small lung volume and a reticular granular appearance with air bronchogram.

Local teams were trained with an instruction manual designed by the researchers. The coordinators of the fieldwork supervised data collection to assure quality control. Data for each newborn were collected using tested instruments (Vermont-Oxford Network modified questionnaire). The outcome variable was surfactant use up to two hours of life. Variables related to hospital characteristics (contextual effects) were complexity of unit classification, number of beds in each unit and existence of the second stage of kangaroo mother care (intermediate care unit in which the mothers remain 24 hours alongside their children, participating in their care and using the kangaroo position).

Units were categorized by the Vermont Oxford Network classification, $2002^{15}$, into less complex ( $3 a$ - units that have capacity to take care of newborns with birth weight $>1000 \mathrm{~g}$ and greater than 28 weeks gestational age, and are able to promote limited life support and conventional ventilator support, and perform minor surgical procedures) or more complex ( $3 \mathrm{~b}$ - units capable of taking care of infants $<1000 \mathrm{~g}$ or $<28$ weeks gestational age, and able to provide advanced respiratory support, which have clinical and surgical specialties, access to imaging and major surgical procedures).

Maternal variables were education (illiterate, primary, secondary and complete or incomplete high education levels) and prenatal care (yes if at least two visits were taken). Newborn variables were gestational age (estimated by the last menstrual period and treated as a continuous vari- able), disease severity index (Score for Neonatal Acute Physiology Perinatal Extension, version II -SNAPPE-II - categorized into < 11, 11-23, 24$32,33-50,>51)^{16}$, weight for gestational age classification (AGA- appropriate for gestational age, SGA - small for gestational age or LGA - large for gestational age - taking into account Battaglia and Lubchenco's intrauterine growth curve ${ }^{17}$ ).

Data were analyzed using the statistical package Stata 12. Multilevel logistic regression with two explanatory levels was performed: Level 1 institutional factors (hospital - contextual effect) and Level 2 - individual factors (characteristics of mothers and newborns) ${ }^{18}$. The choice of variables that entered the initial model was made using a theoretical model of causality. This model included variables related to the mothers (education level and prenatal visits) and newborns (clinical severity, gestational age and SGA classification) (Figure 1). In this analysis six regression models were used, in which the associations between hospital/unit and newborn/mother characteristics and exogenous surfactant therapy use were estimated. In the first model only influences of the hospital/unit variables (contextual effect) were estimated. In the second, all individual variables were added to the model and the contextual effect of the entry of these variables in the model was estimated. In the third, only the individual variables with $p$-value $<0.20$, in addition to the contextual effect, were retained in the model. From the fourth to sixth models the variables related to hospital/unit were added to the models one at a time following the sequence: having the second stage of the Kangaroo Method implemented, hospital complexity and the number of hospital beds. This sequence was performed in order to verify the contribution of each of these

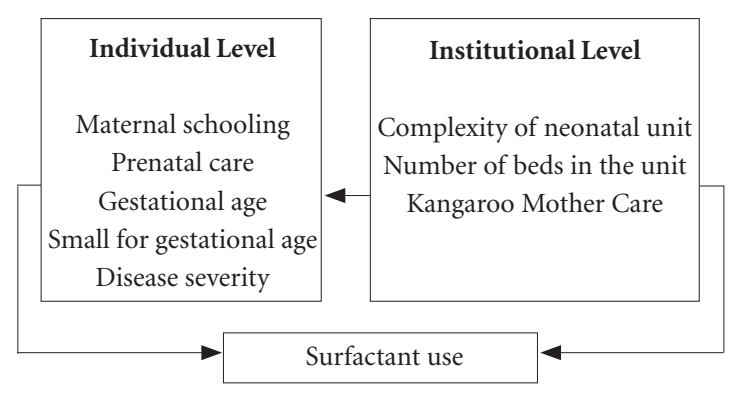

Figure 1. Multilevel model of individual and contextual factors associated with surfactant use. 
variables for the intraclass correlation coefficient (rh), which measures the contextual effect. As each hospital/unit characteristics were included in the model the variation of the coefficient was checked out. This procedure made it possible to measure the specific contribution of each variable to the contextual effect. The magnitudes of the adjusted risk of each individual and contextual variable in relation to the outcome were verified in the last model by calculating the OR values and their confidence intervals.

Differences in surfactant use according to each unit were measured by the residuals of an intercept only multilevel model. In this model the value of the intercept $\beta 0$ represents the effect of an "average" unit on the probability of surfactant use, while the residuals represent deviations of each unit in relation to this overall average. Variations in surfactant use in each of the surveyed units are shown in a caterpillar plot, ordered from the hospital with the lowest to the highest use, along with 95\% confidence intervals of the probability of surfactant use for each unit. As the values were standardized, so the overall average was zero.

The study was approved by the Ethics Committee in Research of each of the units involved.

\section{Results}

Among the 630 infants with RDS, four had no information about the use of surfactant. Sixty-two point five percent of the studied units were classified as less complex (3a) and just over a half, $57.5 \%$ had less than 15 beds.

In Table 1 absolute and relative frequencies or mean \pm standard deviation of individual and institutional characteristics are shown.

Most of mothers (62.6\%) were between 20 and 34 years old and $40.8 \%$ had incomplete primary education. At least two antenatal consultations were held by $76.2 \%$ of mothers and $51.7 \%$ had vaginal delivery. Among the infants with RDS, $84.4 \%$ weighed $<1500 \mathrm{~g}$ at birth, $99.2 \%$ were preterm, $51 \%$ had severity index SNAPPE $\mathrm{II} \leq 23$ and just over half of them (50.5\%) were classified as SGA.

Among the 626 infants analyzed, $82.6 \%$ have been given exogenous surfactant at some time. Among the newborns (NB) for which there was information on the site of use (599), 7.5\% were administered surfactant in the delivery room. Only $24.7 \%$ made early use of this technology (up to two hours after birth).
In the final model, with adjustment for all of the contextual and individual variables, greater disease severity score (SNAP PE II between 33 and 50) was associated with increased surfactant use $(\mathrm{OR}=2.64,95 \% \mathrm{CI} 1.26-5,52)$ and small for gestational age birth $(\mathrm{OR}=0.59,95 \% \mathrm{CI} 0.37$ to $0.95)$ was associated with less use of surfactant. At the context level (hospital) the number of beds in the unit $>15$ (OR $=5.86,95 \%$ CI 2.70 to 12.55), being a high complexity hospital (OR $=1.73,95 \%$ CI 0.99 to 3.01 ) or unit with implemented kangaroo mother care (OR $=2.91,95 \%$ CI 1.36 to 6.24 ), especially units in Rio de Janeiro state $(\mathrm{OR}=16.17,95 \% \mathrm{CI} 6.57$ to 39.78$)$ were associated with greater surfactant use.

An intraclass correlation coefficient (ICC) of 0.30 was found. This means that $30 \%$ of the variance in the use of exogenous surfactant can be assigned to the context level (hospital/unit). The total contextual effect was explained by three institutional variables used in the analysis. The variable "having Kangaroo Mother Care implemented" contributed to $15 \%$ of the variance, as the ICC value fell from $30 \%$ to $15 \%$ when this variable was introduced in the model without the other institutional variables (model 4). The contextual effect dropped from $15 \%$ to $10 \%$ when the variable "level of complexity of the unity" was added to the model. Thus, this variable was responsible for $5 \%$ of the total effect (model 5). The coefficient dropped to zero when the variable "number of beds in the unit" was added to the model (model 6) meaning that this variable contributed to explain $10 \%$ of the overall contextual effect (Table 2).

The probability of surfactant use in the sixteen hospitals is shown in Figure 2. There was great variation in the use of this technology between units, some of them showing intensive use while others used surfactant more restrictedly. Three units had significantly below-average performance, while one showed above average performance (Figure 2).

\section{Discussion}

Variables related to the institutions, specifically to the neonatal units, were important to explain the use of exogenous surfactant in the first two hours of life in infants with RDS in sixteen Brazilian NICU. The size of this importance is demonstrated by the intraclass correlation coefficient of 0.30 , i.e. $30 \%$ of the outcome can be explained by factors related to the hospitals (con- 
Table 1. Absolute and relative frequencies or mean \pm standard deviation of individual and institutional factors associated with failure to use exogenous surfactant in the first two hours of life in newborns with RDS.

\begin{tabular}{|c|c|c|c|c|}
\hline \multirow[b]{2}{*}{ Individual Factors } & Surfactant & Without surfactant & total & \multirow[t]{2}{*}{ p-value } \\
\hline & $\mathbf{N}(\%)$ & $\mathbf{N}(\%)$ & & \\
\hline SNAPPE II & & & & $0.003^{*}$ \\
\hline$<11$ & $112(73.2)$ & $41(26.8)$ & 153 & \\
\hline 11 a 23 & $132(84.6)$ & $24(15.4)$ & 156 & \\
\hline $24-32$ & $78(84.8)$ & $14(15.2)$ & 92 & \\
\hline $33-50$ & $92(87.6)$ & $13(12.4)$ & 105 & \\
\hline$>50$ & $90(90)$ & $10(10)$ & 100 & \\
\hline total & $102(16.8)$ & $504(83.2)$ & 606 & \\
\hline Maternal Schooling (years) & & & & $0.641^{\star}$ \\
\hline 0 & $8(72.73)$ & $3(27.3)$ & 11 & \\
\hline $1-4$ & $202(84.5)$ & $37(15.4)$ & 239 & \\
\hline $5-8$ & $155(82.4)$ & $33(17.5)$ & 188 & \\
\hline $9-11$ & $108(83.1)$ & $22(16.9)$ & 130 & \\
\hline $12+$ & $16(94.1)$ & $1(5.9)$ & 17 & \\
\hline total & $489(83.6)$ & $96(16.4)$ & 585 & \\
\hline Prenatal consultations $\left(\mathrm{n}^{\circ}\right)$ & & & & $0.469^{\star}$ \\
\hline No & $123(15.7)$ & $23(84.2)$ & 146 & \\
\hline Yes & $382(81.6)$ & $86(18.4)$ & 468 & \\
\hline total & $505(82.2)$ & $109(17.7)$ & 614 & \\
\hline NB Small for Gestational Age & & & & $0.170^{\star}$ \\
\hline No & $260(84.7)$ & $47(15.3)$ & 307 & \\
\hline Yes & $252(80.50$ & $61(19.5)$ & 313 & \\
\hline total & $512(82.6)$ & $108(17.4)$ & 620 & \\
\hline \multirow[t]{2}{*}{ Gestational Age (weeks) } & \multicolumn{2}{|c|}{ Mean $( \pm$ SD $)$} & & \\
\hline & $29.49(2.93)$ & $30.13(3.15)$ & & $0.043^{\star *}$ \\
\hline Institutional Factors & $\mathbf{N}(\%)$ & $\mathrm{N}(\%)$ & total & \\
\hline No of beds in unit & & & & $<0.001^{\star}$ \\
\hline$<15$ & $277(77.2)$ & $82(22.8)$ & 359 & \\
\hline$>=15$ & $238(89.8)$ & $27(10.2)$ & 265 & \\
\hline total & $515(82.5)$ & $109(17.5)$ & 624 & \\
\hline Complexity of neonatal unit & & & & $0.003^{*}$ \\
\hline Low $(3 a)$ & $308(79.0)$ & $82(21.0)$ & 390 & \\
\hline $\operatorname{High}(3 \mathrm{~b})$ & $207(88.5)$ & $27(11.5)$ & 234 & \\
\hline total & $515(82.5)$ & $109(17.5)$ & 624 & \\
\hline Kangaroo Mother Care (KMC) & & & & $<0.001^{\star}$ \\
\hline No & $159(76.1)$ & $50(23.9)$ & 209 & \\
\hline Other units with KMC & $144(74.2)$ & $50(25.8)$ & 194 & \\
\hline RJ units with KMC & $214(94.9)$ & $9(4.1)$ & 223 & \\
\hline total & $517(82.6)$ & $109(17.4)$ & 626 & \\
\hline
\end{tabular}

$\mathrm{NB}=$ Newborn. ${ }^{*}=$ Chi square test. ${ }^{* *}=\mathrm{T}$ Student test.

textual effect). The presence of kangaroo mother care, especially in those units located in the state of Rio de Janeiro, was able to explain half of the contextual effect. With regard to factors related to individuals (mothers and children), those NB with greater disease severity in the first 12 hours of life tended to get more surfactant while small for gestational age infants were less likely to receive surfactant.

The contribution of institutional (hospital) and individual factors to explain the use of the exogenous surfactant replacement therapy was 


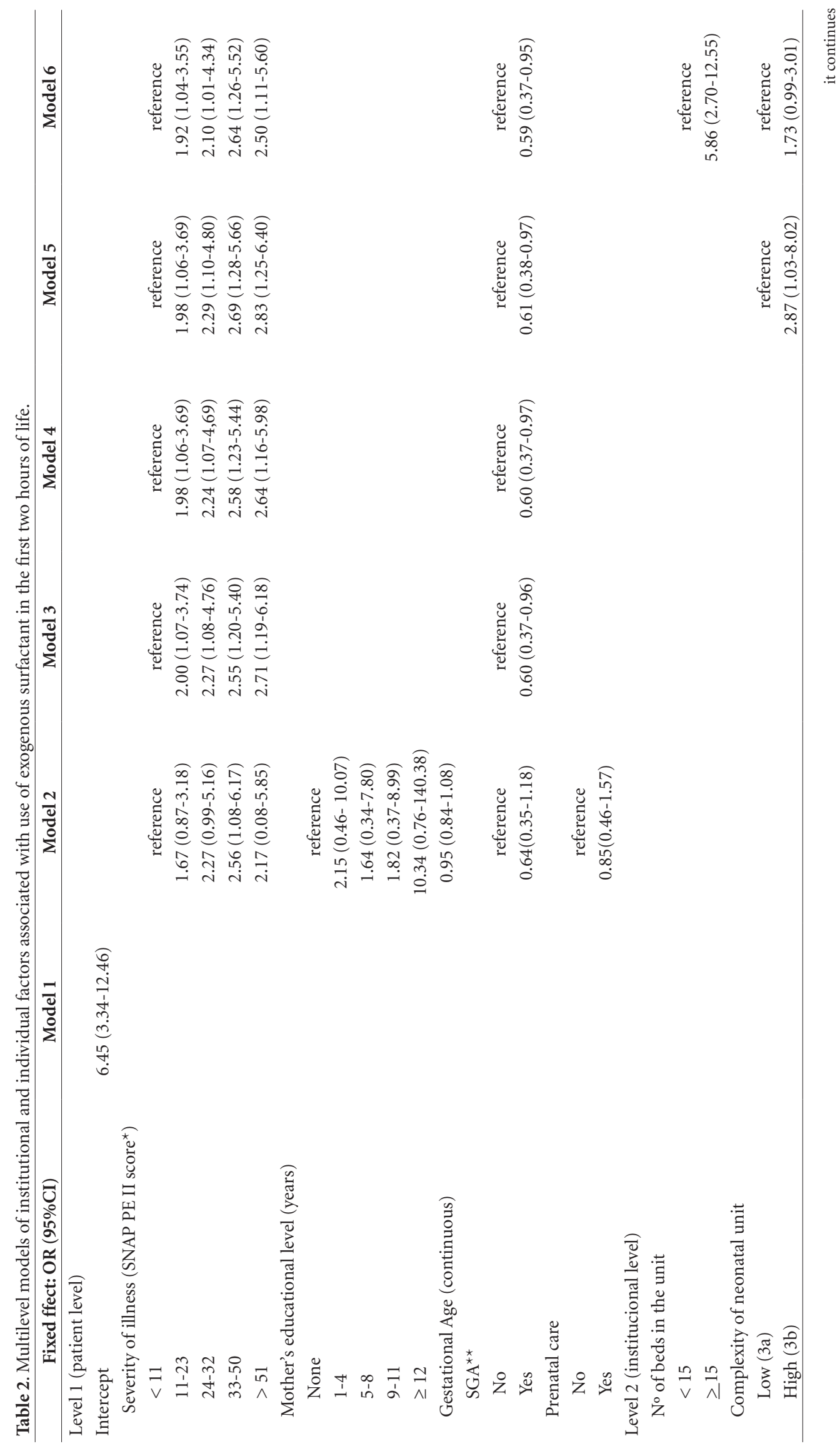




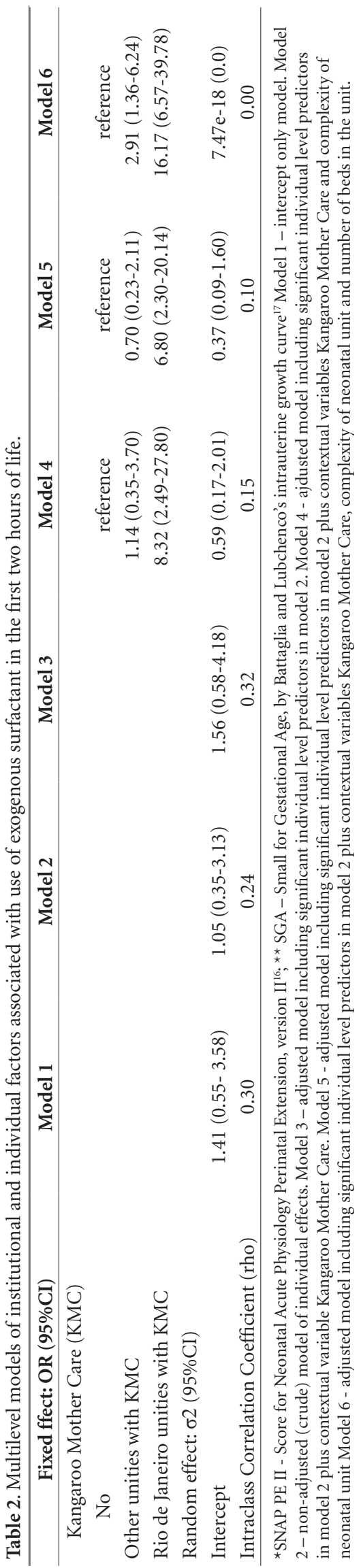

explored by Kaplan et al. ${ }^{11}$, in 2011, also using multilevel analysis. The authors found positive associations with an institutional factor, the rate of annual admissions of extremely low birth weight newborns, and also with some individual factors: white race, male sex, low gestational age and mechanical ventilation in the early hours of hospitalization. However, these authors did not provide the intraclass correlation coefficient, which measures the contribution of the contextual factor to explain the probability of surfactant use. Institutional factors used in Kaplan's model were different from those selected in this study. The admission rate, involvement of the hospital with research, number of surgeries performed and type of funding formed the set of hospital variables in Kaplan's study, whereas in our study we used the number of beds, the degree of complexity of the NICU and implementation of Kangaroo Mother Care. Despite the differences, the two studies accounted for the existence and highlighted the importance of factors linked to two levels of influence (contextual and individual factors) on the use of this technology.

Howell et al. ${ }^{12}$ also demonstrated the contribution of both individual (ethnic group of children), and institutional factors (hospital where children were born), on the use of replacement therapy with exogenous surfactant, but they did not calculate the specific contribution of each factor.

In the present study, we found a contextual effect (pertaining to institutional factors), estimated by the intraclass correlation coefficient (rho) of 0.30 , which means that $30 \%$ of the variance in the use of exogenous surfactant can be attributed to the contextual level. The factor with the greatest contribution to explain the effect of the contextual factor on surfactant use was to be admitted to a NICU of the Rio de Janeiro state, with Kangaroo Mother Care deployed. Probably this was because there was great organizing effort in these units for the implementation of the Kangaroo method at the time of data collection. This action was strongly recommended by the Brazilian Ministry of Health and included the implementation and compliance to protocols during hospitalization, like the use of exogenous surfactant ${ }^{19}$.

Another institutional factor associated with the surfactant use was the number of beds in the neonatal unit. Greater number of beds was associated the greater likelihood of use of this technology. Some authors show better birth outcomes in neonatal units with higher number of admissions per year ${ }^{20}$. Kaplan et al. ${ }^{11}$ have shown 


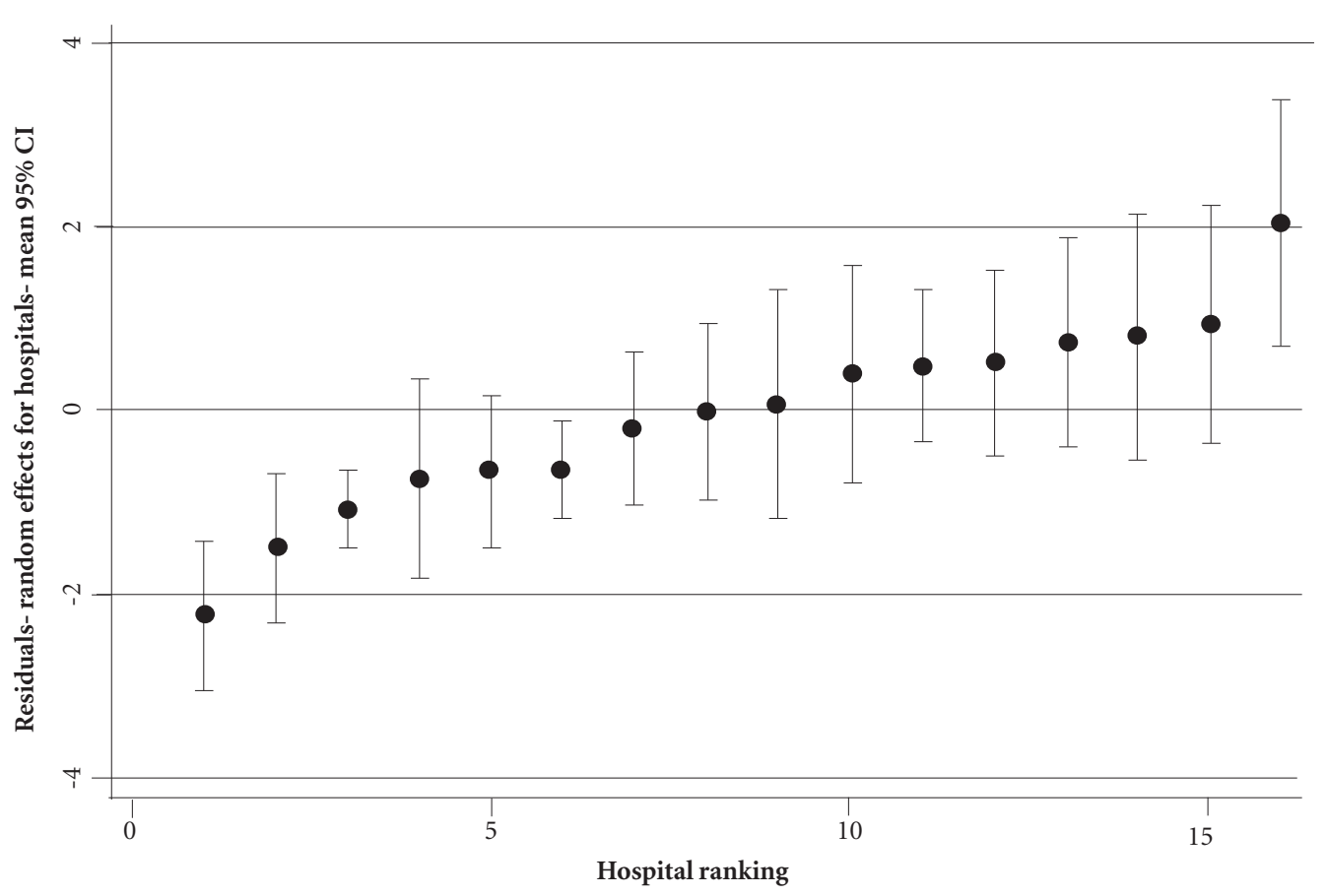

Figure 2. Caterpillar plot presenting mean and $95 \%$ confidence intervals of random effects of surfactant use in the intercept only multilevel model for the 16 hospitals.

that more hospitalizations per year were associated with more intense use of surfactant therapy. It is possible that units with more beds and more admissions per year show better organization and more appropriateness in running protocols. There is evidence of a relationship between higher volume of patients treated in the NICU and better performance and, probably it is a result of greater acquisition of expertise in the care provided $^{20,21}$.

In the present study, the individual factors clinical severity or weight for gestational age classification, in addition to contextual characteristics, were also strongly associated with surfactant use. Newborns with greater disease severity were more likely and SGA NB were less likely to receive the therapy. This result for SGA infants was somewhat unexpected since all infants had RDS and thus have the indication of receiving surfactant. In addition, some authors like Giapros et al. ${ }^{22}$, in 2012, reported that this kind of infants are at higher risk of dying or present adverse pulmonary outcomes such as bronchopulmonary dysplasia (BPD).
This study had some limitations. Some important contextual variables were not collected, since an already existing database had been used. The sample was not probabilistic and, although covering individual units from various regions, it did not allow inferences to the population of these regions to be made. In addition, due to the cross-sectional design it was not possible to verify causal associations between variables. As we considered only the use of surfactant in the first two hours of life the study addressed only the optimal use of this therapy. Therefore, infants who received surfactant after the first two hours were considered to have not received this therapy, since surfactant use after two hours is associated with poorer outcomes ${ }^{7,8,9,10}$.

On the other hand this research brought upon important contributions. The sample size was sufficient to identify some associations and the presence of neonatal units of various regions of the country allowed a broader view of the object studied. Finally, the use of multilevel analysis greatly contributed to the understanding of the involvement of contextual and individual factors 
in the use of this technology in neonates affected by neonatal RDS. In addition, the article fills an important gap in the Brazilian public health evaluation, since there are few studies assessing technology use in high complexity hospitals.

\section{Conclusions}

Although individual clinical features remain having greater weight in determining the use of exogenous surfactant replacement therapy in infants with Respiratory Distress Syndrome, factors linked to the institution are also of great importance. Interventions aimed at modifying institutional factors associated with lower surfactant use are to be encouraged, so that better results on perinatal care could be achieved. It was possible to identify units underperforming the average and to pinpoint that surfactant use is less likely in infants with Intrauterine Growth Restriction (IUGR) or with lower disease severity, all of which require corrective interventions. Special attention needs to be given to promote greater use of surfactant in lower technological complexity units and hospitals with fewer beds, since all infants with RDS have indication for surfactant use in the first two hours of life.

\section{Collaborations}

CCR Lessa participated in the study design, analysis, and final writing of the article; F Lamy Filho and AAM Silva participated in the study design, analysis, and final writing of the article and coordinated the data collection; MEL Moreira, MASM Gomes and ZC Lamy coordinated the collection of data, participated in the final writing and data analysis.

\section{Acknowledgements}

Brazilian Ministry of Health and PAHO. 


\section{References}

1. Fioretto JR, Freddi NA, Costa KN, Nóbrega RF. I Consenso Brasileiro de Ventilação Mecânica em Pediatria e Neonatologia. São Paulo: AMIB; 2012.

2. Neves VC, Koliski A, Dinarte JG. A manobra de recrutamento alveolar em crianças submetidas a ventilação mecânica em unidade de terapia intensiva pediátrica. Rev Bras Ter Intensiva 2009; 21(4):453-460.

3. Freddi NA, Proença Filho JO, Fiori HH. Terapia com surfactante pulmonar exógeno em pediatria. J Pediatr 2003; 79(Supl. 2):205-212.

4. Seger N, Soll R. Animal derived surfactant extract for treatment of respiratory distress syndrome. Cochrane Database Syst Rev 2009; (2):CD007836.

5. Soll RF, Morley CJ. Prophylactic versus selective use of surfactant in preventing morbidity and mortality in preterm infants. Cochrane Database Syst Rev 2001; (2):CD000510

6. Rojas-Reyes MX, Morley CJ, Soll RF. Prophylactic versus selective use of surfactant in preventing morbidity and mortality in preterm infants. Cochrane Database Syst Rev 2012; (3):CD000510.

7. Bahadue FL, Soll RF. Early versus delayed selective surfactant treatment for neonatal respiratory distress syndrome. Cochrane Database Syst Rev 2012; 11:CD001456.

8. Silva CF, Leite AJM, Almeida NMGS, Leon ACMP, Olofin I, Rede Norte-Nordeste de Saúde Perinatal. Fatores associados ao óbito neonatal de recém nascidos de alto risco: estudo multicêntrico em Unidades Neonatais de Alto Risco no Nordeste brasileiro. Cad Saude Publica 2014; 30(2):355-368.

9. Speer CP, Sweet DG, Halliday HL. Surfactant therapy: past, present and future. Early Hum Dev 2013 89(Supl. 1):S22-S24

10. Almeida MFB, Guinsburg R, Martinez FE, Procianoy RS, Leone CR, Marba STM, Rugolo LMSS, Luz JH, Lopes JMA. Fatores perinatais associados ao óbito precoce em prematuros nascidos nos centros da Rede Brasileira de Pesquisas Neonatais. J Pediatr 2008; 84(4):300-307.

11. Kaplan HC, Lorch SA, Pinto-Martin J, Putt M, Silber $\mathrm{JH}$. Assessment of surfactant use in preterm infants as a marker of neonatal intensive care unit quality. $B M C$ Health Services Research 2011; 11:22.

12. Howell EA, Holzman I, Kleinman LC, Wang J, Chassin MR. Surfactant use for premature infants with respiratory distress syndrome in three New York City Hospitals: discordance of practice fom a community clinician consensus standart. J Perinatol 2010; 30(9):590-595.
13. Rebello CM, Nacif LFA, Deutsch AD, Paes AT. Momento do tratamento com surfactante em recém-nascidos com muito baixo peso. Einstein 2010; 8(3 Pt 1):320324.

14. Menezes MAS, Garcia DC, Melo EV, Cipolotti R. Recém-nascidos prematuros assistidos pelo Método Canguru: avaliação de uma coorte do nascimento aos 6 meses. Rev Paul Pediatr 2014; 32(2):171-177.

15. Horbar JD, Carpenter J, editors. Vermont Oxford Network 2001 Database Summary. Burlington: Vermont Oxford Network; 2002.

16. Richardson DK, Corcoran JD, Escobar GJ, Lee SK SNAP-II and SNAPPE-II: simplified newborn illness severity and mortality risk scores. J Pedriatr 2001; 138(1):92-100

17. Battaglia FC, Lubchenco LO. A practical classification of newborn infants by weight and gestational age. $J P e$ diatr 1967; 71(2):159-163.

18. Rabe-Hesketh S, Skrondal A. Multilevel and Longitudinal Modeling Using Stata. Volume I. $3^{\text {th }}$ ed. College Station: Stata Press; 2008.

19. Brasil. Ministério da Saúde (MS). Atenção humanizada ao recém-nascido de baixo peso: Método Canguru. $2^{\text {a }}$ ed. Brasília: Editora do Ministério da Saúde; 2011.

20. Tucker J; UK Neonatal Staffing Study Group. Patient volume, staffing, and workload in relation to risk-adjusted outcomes in a random stratified sample of UK neonatal intensive care units: a prospective evaluation. Lancet 2002; 359(9301):99-107.

21. Phibbs CS, Bronstein JM, Buxton E, Phibbs RH. The effects of patient volume and level of care at the hospital of birth on neonatal mortality. JAMA 1996 276(13):1054-1059.

22. Giapros V, Drougia A, Krallis N, Theocharis P, Andronikou S. Morbidity and mortality patterns in small-for-gestational age infants born preterm. $J \mathrm{Ma}$ tern Fetal Neonatal Med 2012; 25(2):153-157.

Artigo apresentado em 09/12/2015

Aprovado em 01/10/2016

Versão final apresentada em 03/10/2016 